\title{
Seroprevalence and risk factors of infections with Neospora caninum and Toxoplasma gondii in hunting dogs from Campania region, southern Italy
}

\author{
Tereza Machačová ${ }^{1}$, Eva Bártová $^{1}$, Kamil Sedlák $^{2}$, Radka Slezáková ${ }^{\text {, Marie Budíková }}{ }^{3}$, Diego Piantedosi ${ }^{4}$ and \\ Vincenzo Veneziano ${ }^{4}$
}

\author{
${ }^{1}$ Department of Biology and Wildlife Diseases, Faculty of Veterinary Hygiene and Ecology, University of Veterinary and \\ Pharmaceutical Sciences Brno, Czech Republic; \\ ${ }^{2}$ Department of Virology and Serology, State Veterinary Institute, Prague, Czech Republic; \\ ${ }^{3}$ Department of Mathematics and Statistics, Faculty of Science, Masaryk University, Brno, Czech Republic; \\ ${ }^{4}$ Department of Veterinary Medicine and Animal Productions, University of Naples Federico II, Napoli, Italy
}

\begin{abstract}
Hunting dogs have probably a higher level of exposure to Neospora caninum Dubey, Carpenter, Speer, Topper et Uggla, 1988 and Toxoplasma gondii Nicolle et Manceaux, 1908 than other canine populations for their different lifestyle. The aim of our survey was to determine the seroprevalence of $N$. caninum and $T$. gondii in hunting dogs from southern Italy and assess risk factors related to these protozoan infections. Blood samples were collected from 398 hunting dogs (19 different breeds, aged from 5 month to 14 years). The sera were screened by indirect fluorescence antibody test; a titre $\geq 50$ was considered positive. Antibodies to $N$. caninum and $T$. gondii were detected in $59(15 \%)$ dogs with titres from 50 to 3200 and in 94 (24\%) dogs with titres from 50 to 1600 , respectively, with co-infection in $25(6 \%)$ dogs. Statistical difference $(\mathrm{p} \leq 0.05)$ was found only for infection with $T$. gondii between two age groups: $\geq 2-4$ years $(16 \%)$ and $\geq 4-7$ years $(33 \%)$; other observed characteristics were without statistical significance. Our results suggest that the hunting dogs could play an important role in the transmission cycle of $N$. caninum between wild animals and livestock. This is the first detection of antibodies to $T$. gondii in hunting dogs in Italy.
\end{abstract}

Keywords: neosporosis, toxoplasmosis, IFAT, antibody titres, Canis lupus

Neospora caninum Dubey, Carpenter, Speer, Topper et Uggla, 1988 and Toxoplasma gondii Nicolle et Manceaux, 1908 are related coccidians that were considered as the same organism until 1988. The domestic dog (Canis lupus familiaris Linnaeus), coyote (C. latrans Say) and dingo (C. l. dingo Mayer) are definitive hosts for $N$. caninum. Dogs can contract infection of T. gondii as intermediate hosts through ingesting sporulated oocysts in contaminated ground or tissue cysts in raw meat (Otranto et al. 2015). Dogs can also act as mechanical transmitters of oocysts of T. gondii to humans (Lindsay et al. 1997).

The clinical signs of neosporosis are found more frequently in puppies younger than six months, which show ascending paralysis of the limbs associated with high antibody titres up to 5129 (Heckeroth and Tenter 2007). In older dogs reactivation of a chronic subclinical infection may occur with the onset of multifocal central nervous system manifestations and polymiositis, but most of the dogs remain asymptomatic (Dubey and Lappin 2012). General- ised toxoplasmosis can be seen mostly in young dogs aged less than one year and is characterised by fever, tonsillitis, dyspnea, diarrhea and vomiting (Dubey and Lappin 2012).

Infections with $N$. caninum and $T$. gondii are widespread throughout the world and seroprevalence in dogs greatly varies among different geographical regions, living environment or lifestyle (Dubey et al. 2009, Dubey and Schares 2011). There are only few studies focusing on seroprevalence of $N$. caninum and T. gondii in hunting dogs (Ali et al. 2003, Collantes-Fernàndez et al. 2008, Hosseininejad and Hosseini 2011, Maia et al. 2014). Hunting dogs may have a higher level of exposure to these two protists than other canine populations (e.g. household dogs) for their closer contact with wooded and rural areas contaminated by oocysts, and contact with intermediate hosts represented by wild animals.

For this reason the aim of the present survey is to determine the seroprevalence of $N$. caninum and $T$. gondii in hunting dogs from southern Italy, and assess risk factors related to infections with these parasitic protists.

Address for correspondence: E. Bártová, Department of Biology and Wildlife Diseases, Faculty of Veterinary Hygiene and Ecology, University of Veterinary and Pharmaceutical Sciences Brno, Palackého tř. 1946/1, 61242 Brno, Czech Republic. Phone: +420 541562633; Fax: +420 541 562633; E-mail: bartovae@vfu.cz 
Table 1. Distribution of antibody titres in hunting dogs positive to Neospora caninum Dubey, Carpenter, Speer, Topper et Uggla, 1988 and Toxoplasma gondii Nicolle et Manceaux, 1908.

\begin{tabular}{|c|c|c|c|c|c|c|c|c|}
\hline \multirow{2}{*}{ Parasite } & \multirow{2}{*}{$\begin{array}{l}\text { Number of } \\
\text { positive dogs }\end{array}$} & \multicolumn{7}{|c|}{ Antibody titres in indirect fluorescence antibody test } \\
\hline & & 50 & 100 & 200 & 400 & 800 & 1600 & 3200 \\
\hline Neospora caninum & 59 & $31(53 \%)$ & $15(25 \%)$ & $4(7 \%)$ & $5(9 \%)$ & $2(3 \%)$ & $1(2 \%)$ & $1(2 \%)$ \\
\hline Toxoplasma gondii & 94 & $21(22 \%)$ & $29(31 \%)$ & $23(24 \%)$ & $10(11 \%)$ & $9(10 \%)$ & $2(2 \%)$ & - \\
\hline
\end{tabular}

\section{MATERIALS AND METHODS}

\section{Study area and hunting dogs}

The survey was conducted on 398 hunting dogs from $76 \mathrm{mu}-$ nicipalities located in two provinces (Avellino and Salerno) during the years 2013-2014. Avellino (4054'55"N; 14²4'22"E) and Salerno $\left(40^{\circ} 41^{\prime} 00^{\prime \prime} \mathrm{N} ; 1^{\circ} 47^{\prime} 00^{\prime \prime E}\right)$ provinces belong to the Campania region in southern Italy. The territories are contiguous and overlook the Tyrrhenian Sea.

The sample size was calculated using the formula proposed by Thrusfield (2007) for a theoretically 'infinite' population inserting the following data: expected prevalence $11 \%$ based on the results of a previous survey on Neospora caninum in a large dog population in Campania region (Cringoli et al. 2002); confidence interval (99\%) and desired absolute precision (5\%). This study was approved by the Ethical Animal Care and Use Committee of the Department of Veterinary Medicine and Animal Productions - University of Naples Federico II, and consent was obtained from the owners of the hunting dogs.

A questionnaire was submitted to the hunters in order to obtain information about age, gender, breed, size, cohabitation of several dogs (packs of dogs), contact with other pet or farm animals (cats, horses and ruminants) and hunted species (game birds, wild boars, foxes and hares). Overall, the average age of the hunting dog population was 3.5 years (ranging from 5 months to 14 years). Animals were divided by age into four groups: $<2$ years, $\geq 2-4$ years, $\geq 4-7$ years, $\geq 7$ years. There were 232 males and 166 females, including the following breeds: 139 Italian segugio, 113 English setter, 28 Epagneul breton, 19 mixed-breeds, 17 Beagle, 16 Griffon bleu de Gascogne and 66 of other breeds (with number of dogs below 16). On the basis of the height to the withers, according to Wanha et al. (2005), the dogs were divided in groups of small size $(\leq 39 \mathrm{~cm})$, medium $(40-59 \mathrm{~cm})$ and large $(60-70 \mathrm{~cm})$. Almost all of dogs lived in a rural environment and the pack size was variable from 1 to more than 13 dogs. Regarding the type of hunting, we created two categories: game fur animals (wild boars, hares and foxes) and game birds (migrating and non-migrating). The majority of dogs (359/398) were in contact with pet or farm animals. A complete clinical examination was performed on each animal.

\section{Sera preparation and serological tests}

Blood sampling was performed in 41 private veterinary hospitals located in the study area. After the dogs had fasted overnight, $5 \mathrm{ml}$ of blood was withdrawn from the cephalic vein, collected into vacuum tubes without an anticoagulant agent (Becton Dickinson, Vacutainer ${ }^{\circledR}$, Franklin Lakes, NJ, USA). Sera were obtained by centrifugation for $10 \mathrm{~min}$ at $358 \mathrm{~g}$ and stored at $-20^{\circ} \mathrm{C}$ until assayed at the Department of Virology and Serology, State Veterinary Institute, Prague.
The presence of antibodies to N. caninum and Toxoplasma gondii was detected by indirect fluorescence antibody test (IFAT) using a commercially available antigen of $N$. caninum and $T$. gondii IFR (Veterinary Medical Research \& Development = VMRD, Pullman, Chicago, USA) and anti-dog IgG FITC conjugate (VMRD). The sera were diluted with phosphate buffered saline two-fold starting at titre 1:50; a titre of 50 was considered positive for both parasites. Procedure in brief: antigens of $N$. caninum or $T$. gondii fixed on glass slides were overlaid with $15 \mu \mathrm{l}$ of the examined serum and incubated in a humid chamber $30 \mathrm{~min}$ at $37^{\circ} \mathrm{C}$ followed by washing $(2 \times 10 \mathrm{~min})$, drying and applying $15 \mu \mathrm{l}$ of specific conjugate. Then, the slides were incubated $30 \mathrm{~min}$ at $37^{\circ} \mathrm{C}$ in a humid chamber. After washing $(2 \times 10 \mathrm{~min})$ and drying, the slides were overlaid with $80 \%$ glycerol $(\mathrm{pH} 7.4$ ) and covered with cover slip and examined with fluorescence microscope Olympus BX 41 at $1000 \times$ magnification with oil immersion. Continuous peripheral fluorescence was considered specific. Sera from dogs simultaneously positive or negative in both latex agglutination test (LAT) and IFAT served as positive and negative controls of $N$. caninum and $T$. gondii and were included in each slide.

\section{Statistical analysis}

Seroprevalence was statistically analysed, considering the variables of gender, age, breed, size of dogs, size of dog pack, locality where they live (rural and urban), contact with other animals and hunted species. The data analysis was performed with Pearson Chi-Square test for independence or with Fisher exact test (in case of characteristic with only two variants) using STATISTICA Cz 12 (StatSoft, Inc. 2013). Dependence of age and seroprevalence was evaluated by Wilcoxon test. We tested the null hypothesis that $N$. caninum and $T$. gondii seroprevalence does not depend on gender, age and breeds and other factors. The differences were considered statistically significant when $p$-value was $\leq 0.05$. Dogs from groups with unknown data were not included in statistic evaluation.

\section{RESULTS}

Antibodies against Neospora caninum and Toxoplasma gondii were found in 59 (15\%; 95\% CI: 11-18\%) dogs, with titres ranging from 50 to 3200 , and in 94 (24\%; 95\% CI: $19-28 \%$ ) dogs, with titres ranging from 50 to 1600 , respectively; $6 \%(25 / 398 ; 95 \%$ CI: $4-9 \%)$ of dogs was co-infected by both protists (Table 1).

Table 2 shows the results of the seroprevalence analysis in relation to the detailed characteristics of the canine population hypothesised to be associated with the occurrence of $N$. caninum and T. gondii. Higher prevalence of antibodies against $N$. caninum was detected in females $(18 \%$; 29/166; 
Table 2. Characteristics of hunting dogs and their seroprevalence against Neospora caninum Dubey, Carpenter, Speer, Topper et Uggla, 1988 and Toxoplasma gondii Nicolle et Manceaux, 1908.

\begin{tabular}{|c|c|c|c|c|c|}
\hline \multirow{2}{*}{ Characteristics } & \multirow{2}{*}{ Dogs tested } & \multicolumn{2}{|c|}{ Neospora caninum } & \multicolumn{2}{|c|}{ Toxoplasma gondii } \\
\hline & & IFAT positive (\%) & IC $95 \%$ & IFAT positive (\%) & IC $95 \%$ \\
\hline \multicolumn{6}{|l|}{ Gender } \\
\hline Female & 166 & $29(18 \%)$ & $12-23 \%$ & $33(20 \%)$ & $14-26 \%$ \\
\hline Male & 232 & $30(13 \%)$ & $9-17 \%$ & $61(26 \%)$ & $21-32 \%$ \\
\hline \multicolumn{6}{|l|}{ Age categories (years) } \\
\hline$<2$ & 99 & $10(10 \%)$ & $4-16 \%$ & $22(22 \%)$ & $14-30 \%$ \\
\hline$\geq 2-4$ & 126 & $17(14 \%)$ & $8-20 \%$ & $20(16 \%)^{*}$ & $10-22 \%$ \\
\hline$\geq 4-7$ & 126 & $23(18 \%)$ & $12-25 \%$ & $42(33 \%)^{*}$ & $25-42 \%$ \\
\hline$\geq 7$ & 47 & $9(19 \%)$ & $8-30 \%$ & $10(21 \%)$ & $10-33 \%$ \\
\hline \multicolumn{6}{|l|}{ Breed } \\
\hline Segugio & 139 & $20(14 \%)$ & $9-20 \%$ & $35(25 \%)$ & $18-32 \%$ \\
\hline Setter & 113 & $18(16 \%)$ & $9-23 \%$ & $26(23 \%)$ & $15-31 \%$ \\
\hline Breton & 28 & $4(14 \%)$ & $1-27 \%$ & $8(29 \%)$ & $12-45 \%$ \\
\hline Mixed-breed & 19 & $2(11 \%)$ & $0-24 \%$ & $4(21 \%)$ & $3-39 \%$ \\
\hline Beagle & 17 & $5(29 \%)$ & $8-51 \%$ & $4(24 \%)$ & $3-44 \%$ \\
\hline Griffon & 16 & $2(13 \%)$ & $0-29 \%$ & $2(13 \%)$ & $0-29 \%$ \\
\hline Others** & 66 & $1(2 \%)$ & $4-20 \%$ & $15(23 \%)$ & $13-33 \%$ \\
\hline \multicolumn{6}{|l|}{ Height to the withers $(\mathrm{cm})$} \\
\hline Small $(\leq 39)$ & 11 & $1(9 \%)$ & $0-26 \%$ & $2(18 \%)$ & $0-41 \%$ \\
\hline Medium (40-59) & 295 & $46(16 \%)$ & $12-20 \%$ & $72(24 \%)$ & $20-29 \%$ \\
\hline Large (60-70) & 92 & $12(13 \%)$ & $6-20 \%$ & $20(22 \%)$ & $13-30 \%$ \\
\hline \multicolumn{6}{|l|}{ Size of dog packs } \\
\hline Only one dog & 33 & $5(15 \%)$ & $3-27 \%$ & $5(15 \%)$ & $3-27 \%$ \\
\hline$\geq 2-6$ & 222 & $34(15 \%)$ & $11-20 \%$ & $62(28 \%)$ & $22-34 \%$ \\
\hline$\geq 6-13$ & 94 & $11(12 \%)$ & $5-18 \%$ & $17(18 \%)$ & $10-26 \%$ \\
\hline$\geq 13$ & 45 & $9(20 \%)$ & $8-32 \%$ & $9(20 \%)$ & $8-32 \%$ \\
\hline Unknown & 4 & $0(0 \%)$ & - & $1(25 \%)$ & $0-67 \%$ \\
\hline \multicolumn{6}{|l|}{ Locality of living } \\
\hline Rural & 391 & $58(15 \%)$ & $11-18 \%$ & $90(23 \%)$ & $19-27 \%$ \\
\hline Urban & 6 & $1(17 \%)$ & $0-47 \%$ & $4(67 \%)$ & $29-100 \%$ \\
\hline Unknown & 1 & 0 & - & 0 & - \\
\hline \multicolumn{6}{|l|}{$\begin{array}{l}\text { Contact with other pet or } \\
\text { farm animals }\end{array}$} \\
\hline No & 38 & $5(13 \%)$ & $2-24 \%$ & $7(18 \%)$ & $6-31 \%$ \\
\hline Yes & 359 & $54(15 \%)$ & $11-19 \%$ & $87(24 \%)$ & $20-29 \%$ \\
\hline Unknown & 1 & 0 & - & 0 & - \\
\hline \multicolumn{6}{|l|}{ Hunted animals } \\
\hline Game fur animals $* * *$ & 220 & $30(14 \%)$ & $9-18 \%$ & $52(24 \%)$ & $18-29 \%$ \\
\hline Game birds & 177 & $29(16 \%)$ & $11-22 \%$ & $42(24 \%)$ & $18-30 \%$ \\
\hline Unknown & 1 & 0 & - & 0 & - \\
\hline
\end{tabular}

* values significantly different ( $\mathrm{p}$-value $<0.05$ ) between groups are labeled with an asterisk; ** breeds including less than 16 dogs; *** game fur animals (boars, foxes, hares).

95\% CI: $12-23 \%)$ compared to males $(13 \% ; 30 / 232 ; 95 \%$ CI: $9-17 \%)$, but without statistical difference. In contrast, higher prevalence of antibodies to $T$. gondii was detected in males $(26 \% ; 61 / 232 ; 95 \%$ CI: $21-32 \%)$ compared to females $(20 \%$; 33/166; 95\% CI: $14-26 \%)$, but also without statistical difference. Statistically significant difference ( $p=0.0134, \mathrm{OR}=2.7,95 \% \mathrm{CI}: 2-5 \%$ ) was found for infection with $T$. gondii between two age groups: $\geq 2-4$ years (16\%, 95\% CI: $10-22 \%)$ and $\geq 4-7$ years $(33 \%, 95 \% \mathrm{CI}$ : 25-42\%); other observed characteristics were without statistical significance.

Clinical examination of the seropositive dogs did not show any evidence of abnormalities referable to infection with these two protists.

\section{DISCUSSION}

In Italy, Neospora caninum and Toxoplasma gondii are widespread in wild animals such as wild boars (Ranuc- ci et al. 2013), wild rabbits (Zanet et al. 2013) and hares (Abramo et al. 1997). Gondim et al. (2004) demonstrated a sylvatic transmission cycle of $N$. caninum between wild animals and canids. These authors transmitted $N$. caninum from white-tailed deer (Odocoileus virginianus Zimmermann) to dog through feeding with brain tissue and from the latter to calf by ingestion of the excreted oocysts, suggesting an important role for hunting dogs in the crossover cycle between wild animals and livestock. Regarding T. gondii, there are not wild felines that may contaminate the wooded environment in southern Italy. However, we have to take into account excretion of oocysts in the faeces of stray cats, whose number is considerable (Otranto et al. 2015). Hunting dogs are more exposed to infections with $N$. caninum and $T$. gondii for their outdoor lifestyle and the habit of hunters of eviscerating carcasses in the field. Furthermore, some hunters in southern Italy offer viscera, 
tissues and portion of muscles of hunted animals to their dogs as a reward for their ability.

Our results suggest that there is a discrete level of exposure to infections with $N$. caninum and $T$. gondii for hunting dogs living in southern Italy. The finding of a lower seroprevalence for $N$. caninum (15\%) than T. gondii (24\%) is in agreement with the general trend reported in dogs from different countries (e.g. Wahna et al. 2005, Nguyen et al. 2012, Langoni et al. 2013), indicating that $T$. gondii is probably more widespread. The seroprevalence of antibodies against $N$. caninum found in our study is similar to the $15 \%$ prevalence reported by Cringoli et al. (2002) using IFAT in a smaller number of hunting dogs $(n=99)$ tested as a part of a larger survey in 1058 dogs from Campania region. A similar prevalence (15\%) was reported by Capelli et al. (2004) in a study in northeastern Italy in 95 hunting dogs tested by ELISA. A higher prevalence of $N$. caninum (23\%) was detected in 100 hunting dogs from Spain (Collantes-Fernàndez et al. 2008) whereas dogs from Portugal showed a much lower infection level $(2 \% ; n=59)$ (Maia et al. 2014). Some studies showed a significantly higher seroprevalence to $N$. caninum in farm, stray and hunting dogs than in household dogs (Sager et al. 2006, Paradies et al. 2007, Collantes-Fernàndez et al. 2008, Maia et al. 2014). Similarly, hunting dogs in our study showed a higher level of antibodies to $N$. caninum compared to $6 \%$ and $12 \%$ prevalence detected in household dogs in previous studies from Italy (Cringoli et al. 2002, Capelli et al. 2004), respectively.

The prevalence of antibodies against $T$. gondii found in our study is in the range of seroprevalence found in 51 hunting dogs $(20 \%)$ from the northeastern Taiwan (Fan et al. 1998) and 59 hunting dogs (31\%) from Trinidad and Tobago (Ali et al. 2003). To our knowledge this is the first study of seroprevalence of $T$. gondii on the population of hunting dogs, and in general in canine species, in Italy. In the literature, higher seroprevalence of $T$. gondii was recorded in farm, stray and hunting dogs than in household dogs (Ali et al. 2003, Nguyen et al. 2012, Otranto et al. 2015), probably related to the carnivorous behavior of dogs living outdoor by eating prey animals such as small mammalian (e.g rodents) and birds. A moderate percentage of the dogs examined in present study were positive for both protists $(6 \%)$. There are few data about co-infection in dogs ranging from $1 \%$ to $9 \%$ (Hosseininejad and Hosseini 2011, Nguyen et al. 2012).

Regarding the gender of dogs, this study did not show any significant difference in seroprevalence for both protists, which is in agreement with many previous studies (e.g. Lopes et al. 2011, Nguyen et al. 2012, Alvarado-Esquivel et al. 2014, Maia et al. 2014). Regarding N. caninum, most of epidemiological surveys indicated no association with breed, but a higher seroprevalence was observed in pure breeds in Italy (Cringoli et al. 2002, Capelli et al. 2004). Collantes-Fernàndez et al. (2008) found higher seroprevalence in mixed-breed dogs in Spain, but concluded that this result was probably biased because the large part of their sample was represented by mixed breed animals. However, the breed of hunting dogs was not a significant factor for the presence of infection with $N$. caninum in our study.

Our findings of a gradual increase of seroprevalence for both protists with age are in agreement with other reports (Ali et al. 2003, Ahmad et al. 2014), although the increasing age was a risk factor only for $T$. gondii. The observed higher seroprevalence in older dogs suggests that the infections are mainly maintained by horizontal rather than vertical transmission. Other epidemiological factors, such as dog's size, pack size, contact with pet or farm animals and hunted species were not associated with higher seroprevalence against both parasites. Wahna et al. (2005) found no differences in dogs of different sizes, while $N$. caninum seroprevalence was associated with living with other dogs (Capelli et al. 2004).

In conclusion, hunting dogs in southern Italy may be considered to be in risk for infection with both protists and they may play an important role in the transmission cycle of $N$. caninum between wild animals and livestock.

Acknowledgements. The study was supported by the management committees of the hunting districts of Salerno (ATC SA 1) and Avellino (ATC AV). The authors thank Dr. Gennaro Barra, Dr. Antonio Raffaele and Mr. Carlo Cascino for their technical assistance and logistical support.

\section{REFERENCES}

Abramo F., Mancianti F., Di Martino R., Poli A. 1997: Toxoplasmosis in European brown hares in the Province of Pisa (Italy). In: "In memoriam" al Professor Doctor D.F. de P. Martìnez Gòmez. Facultà di Medicina Veterinaria di Cordoba, Cordoba, pp. 96-106.

Ahmad N., Ahmed H., Irum S., Qayyum M. 2014: Seroprevalence of $\mathrm{IgG}$ and $\mathrm{IgM}$ antibodies and associated risk factors for toxoplasmosis in cats and dogs from subtropical arid parts of $\mathrm{Pa}$ kistan. Trop. Biomed. 31: 777-784.

Ali N., Harris J.A., Watkins J.D., Adesiyun A.A. 2003: Seroepidemiology of Toxoplasma gondii in dogs in Trinidad and Tobago. Vet. Parasitol. 113: 179-187.

Alvarado-Esquivel C., Romero-Salas D., Cruz-Romero A., García-Vázquez Z., Peniche-Cardeña Á., Ibarra-Priego N., Ahuja-Aguirre C., Pérez-de-León A.A., Dubey
J.P. 2014: High prevalence of Toxoplasma gondii antibodies in dogs in Veracruz, Mexico. BMC Vet. Res. 10: 191- 195.

Capelli G., Nardelli S., Di Regalbono A.F., Scala A., Pietrobelli M. 2004: Seroepidemiological survey of Neospora caninum infection in dogs in north-eastern Italy. Vet. Parasitol. 123: $143-148$.

Collantes-Fernández E., Gómez-Bautista M., Miró G., Álvarez-García G.A, Pereira-Bueno J., Frisuelos C., Ortega-MorA L.M. 2008: Seroprevalence and risk factors associated with Neospora caninum infection in different dog populations in Spain. Vet. Parasitol. 152: 148-151.

Cringoli G., Rinaldi L., Capuano F., Baldi L., Veneziano V., CAPelli G. 2002: Serological survey of Neospora caninum and Leishmania infantum co-infection in dogs. Vet. Parasitol. 106: 307-313. 
Dubey J.P., LAPPIN M.R. 2012: Toxoplasmosis and neosporosis. In: C.E. Greene (Ed.), Infectious Diseases of Dog and Cat. Fourth Edition. Elsevier, St. Louis, Missouri, pp. 806-827.

Dubey J.P., LindSAY D.S., LAPPIN M.R. 2009: Toxoplasmosis and other intestinal coccidial infections in cats and dogs. Vet. Clin. North. Am. Small. Anim. Pract. 39: 1009-1034.

Dubey J.P., Schares G. 2011: Neosporosis in animals - the last five years. Vet. Parasitol. 180: 90-108.

Fan C.K., Su K.E., Chung W.C., Tsai Y.J., Chiou H.Y., Lin C.F., Su C.T., Tsai M.C., Chao P.H. 1998: Seroprevalence of Toxoplasma gondii antibodies among Atayal aboriginal people and their hunting dogs in northeastern Taiwan. Jpn. J. Med. Sci. Biol. 51: 35-42.

Gondim L.F.P., Mcallister M.M., Mateus-Pinilla N.E., Pitt W.C., Mech L.D., Nelson M.E. 2004: Transmission of $\mathrm{Ne}$ ospora caninum between wild and domestic animals. J. Parasitol. 90: 1361-1365.

Heckeroth A.R., Tenter A.M. 2007: Immunoanalysis of three litters born to a Doberman bitch infected with Neospora caninum. Parasitol. Res. 100: 837-846.

Hosseininejad M., Hosseini F. 2011: Seroprevalence of $\mathrm{Ne}$ ospora caninum and Toxoplasma gondii infection in dogs from west and central parts of Iran using two indirect ELISA tests and assessment of associate risk factors. Iran. J. Vet. Res. 12: 46-51.

Langoni H., Fornazari F., Costa Da Silva R., Monti E.T., Villa F.B. 2013: Prevalence of antibodies against Toxoplasma gondii and Neospora caninum in dogs. Braz. J. Microbiol. 44: 1327-1330.

Lindsay D.S., Dubey J.P., Butler J.M., Blagburn B.L. 1997: Mechanical transmission of Toxoplasma gondii oocysts by dogs. Vet. Parasitol. 73: 27-33.

Lopes A.P., Santos H., Neto F., Rodrigues M., Kwok O.C., Dubey J.P., CARdoso L. 2011: Prevalence of antibodies to Toxoplasma gondii in dogs from northeastern Portugal. J. Parasitol. 97: 418-420.

Maia C., Cortes H., Branca H., Lopes A.P., Pimenta P., Campino L., Cardoso L. 2014: Prevalence and correlates of antibodies to Neospora caninum in dogs in Portugal. Parasite 21: 29

Nguyen T.T., Choe S.E., Byun J.W., Koh H.B., Lee H.S., Kang S.W. 2012: Seroprevalence of Toxoplasma gondii and Neospora caninum in dogs from Korea. Acta Parasitol. 57: 7-12.

Otranto D., Cantacessi C., Pfeffer M., Dantas-Torres F., Brianti E., Deplazes P., Genchi C., Guberti V., Capelli G. 2015: The role of wild canids and felids in spreading parasites to dogs and cats in Europe. Part I: Protozoa and tick-borne agents. Vet. Parasitol. 213: 12-23.

Paradies P., Capelli G., Testini G., Cantacessi C., Trees A.J., Otranto D. 2007: Risk factors for canine neosporosis in farm and kennel dogs in southern Italy. Vet. Parasitol. 145: $240-244$.

Ranucci D., Veronesi F., Moretti A., Branciari R., Miraglia D., Manfredi M.T., Fioretti D.P. 2013: Seroprevalence of Toxoplasma gondii in wild boars (Sus scrofa) from Central Italy. Parasite 20: 1-4.

Sager H., Moret C., Müller N., Staubli D., Esposito M., Schares G., Hässig M., StÄrk K., Gottstein B. 2006: Incidence of Neospora caninum and other intestinal protozoan parasites in populations of Swiss dogs. Vet. Parasitol. 139: 84-92.

Statsoft, InC. 2013: STATISTICA (data analysis software system), version 12. www.statsoft.com.

Thrusfield M. 2007: Veterinary Epidemiology. Third Edition. Wiley-Blackwell, London, 624 pp.

Wahna K., Edelhofer R., Gabler-Eduardo C., Prosla H. 2005: Prevalence of antibodies against Neospora caninum and Toxoplasma gondii in dogs and foxes in Austria. Vet. Parasitol. 128: 189-193.

Zanet S., Palese V., Trisciuoglio A., Cantón Alonso C., Ferroglio E. 2013: Encephalitozoon cuniculi, Toxoplasma gondii and Neospora caninum infection in invasive eastern cottontail rabbits (Sylvilagus floridanus) in northwestern Italy. Vet. Parasitol. 197: 682-684. 